\title{
Histopathological Evaluation of Burn Injury
}

\author{
Anil Kumar Malik ${ }^{1}$, Kunal Khanna ${ }^{2}$, Suresh Kumar Dhattarwal ${ }^{3}$, Meenu Gill ${ }^{4}$ \\ ${ }^{1}$ Associate Professor, Department of Forensic Medicine, Gian Sagar Medical college \& Hospital, Ram Nagar, Rajpura, Patiala, \\ Punjab, India \\ ${ }^{2}$ Assistant Professor, Department of Forensic Medicine, Kalpana Chawla Government Medical College \& Hospital, Karnal, Haryana, \\ India \\ ${ }^{3}$ Senior Professor \& Head, Department of Forensic Medicine, Pt.B.D.Sharma PGIMS, Rohtak, Haryana, India \\ ${ }^{4}$ Professor, Department of Pathology, Pt.B.D.Sharma PGIMS, Rohtak, Haryana, India
}

\begin{abstract}
Background: Burns always have posed a threat to the sensitive human body. It is a common catastrophe today as burn injury cases are one of the common emergencies admitted to any hospital. In a medico-legal setting, the main difficulty arises when a burnt body found in unknown circumstances is brought for post-mortem examination. In such a case, a forensic expert has to opine whether the burn injuries sustained are antemortem or post-mortem. It is also of paramount importance to determine the age of burn injuries sustained. Aging of burn injuries by the naked eye is sometimes difficult and unreliable. By histopathological examination of burnt tissue, one can predict whether the victim was alive or dead when the fire was going on and determine the age of burn injuries.

Materials and Methods: The present cross-sectional study was carried out in the Department of Forensic Medicine \& Toxicology, Pt. B.D.Sharma PGIMS, Rohtak. Total 3033 autopsies were conducted in the mortuary of the Department of Forensic Medicine \&Toxicology, PGIMS, Rohtak, from November 5, 2011 'to November 5, 2013. During that period, out of 486 cases reported burns, randomly 100 cases were selected for this study.

Results and Conclusions: In the present study, efforts were made to determine burn wound vitality and age by histopathological evaluation. The study revealed that the inflammatory infiltrate consisted mainly of polymorphonuclear leucocytes in initial stages (up to $3^{\text {rd }}$-day post-burn) with gradual lymphocytes, macrophages, and fibroblasts forming immature granulation tissue. On the 14th-day post-burn, the burn wound revealed repair by regeneration, increased collagen deposition, fibrosis, and granulation tissue formation. It was infiltrated with fibroblasts, macrophages, and lymphocytes. Our study demonstrated that evaluation of various histopathological changes occurring during the distinctive phases of burn wound healing help in the estimation of its vitality and age.
\end{abstract}

Keywords: Age of burn, Burn, Histopathological evaluation, Medico-legal, Vitality.

Int J Eth Trauma Victimology (2021). DOI: 10.18099/ijetv.v7i01.2

\section{INTRODUCTION}

$\mathrm{F}$ orensic medicine deals with the application of medical knowledge to aid in the administration of justice. So far as the modes of sustaining burn injuries in India are concerned, the same is everywhere else, i.e., flames, thermal, scalds, and electrical burns. In our country, the most common manner of sustaining flame burns is accidental. ${ }^{1}$

The main difficulty arises when a dead body is brought to a forensic expert for opinion in a state of partial skeletonization from burning as well as from advanced putrefaction or the body of a victim who has been killed or murdered by throttling, poisoning or by some other means. Later the body is burnt to conceal the crime and to make it appear like death from burning. As severe burning or charring of the body might produce artifacts of heat ruptures that may resemble lacerated or even incised wounds, differentiation requires differentiation. Therefore, differentiation of antemortem and post-mortem burns need to be affirmatively ascertained. It is also of paramount importance whether a burn injury has a vital reaction, and if so, how long before the burn injury has been sustained.
Corresponding Author: Dr. Anil Kumar Malik, Associate Professor, Department of Forensic Medicine, Gian Sagar Medical College and Hospital, Ram Nagar, Rajpura, Patiala, India, e-mail: autopsysurgeon@gmail.com

How to cite this article: Malik AK, Khanna K, Dhattarwal SK, Gill M. Histopathological Evaluation of Burn Injury. Int J Eth Trauma Victimology. 2021;7(1):5-10.

Source of support: Nil

Conflict of interest: None

Received: 04/06/2021;

Accepted: 12/06/2021;

Received in revised form: 04/06/2020; Published:25/06/2020

Forensic experts can determine how long a victim has been exposed by estimating the age of burn injuries. However, the aging of burn injuries by the naked eye is sometimes difficult and unreliable. ${ }^{2}$ By histopathological examination of burnt tissue, one can surely predict whether the victim was alive or dead when fire was going on and determine the age of burn injuries. Walcher pointed the importance of studying the lesions microscopically in order to distinguish between antemortem and post-mortem injuries. According to him, the leucocytic reaction was the earliest histological sign of 
inflammation. The pavement of the inner vessels walls by leucocytes and the beginning of their extravasation may be seen during the first hours after wounding. ${ }^{3}$

Mallik described histological methods of distinguishing antemortem and post-mortem burns using burns inflicted experimentally on guinea pigs, burns of human skin obtained from autopsy examinations, and burns inflicted experimentally in amputated human tissues. In human burns, the earliest histological change in the antemortem burn was leucocytic infiltration at 6 hours after burning. ${ }^{4}$

The present study was conducted to assess the burn wound vitality and age by histopathological examination of burnt tissue.

\section{Materials and Methods}

The present cross-sectional study was carried out in the Department of Forensic Medicine \& Toxicology, Pt. B.D.Sharma PGIMS, Rohtak. Total 3033 autopsies were conducted in the mortuary of the Department of Forensic Medicine \&Toxicology, PGIMS, Rohtak, from November 5, 2011 'to November 5, 2013. During that period, out of 486 cases reported of burns, randomly 100 cases were selected for this study. The ethical approval was taken from Institutional Ethical Committee. After obtaining informed expressed consent, the relevant information regarding the case was collected from accompanying relatives, hospital records, and inquest papers. For the purpose of the study, burn injury was defined as a body lesion due to an external cause, either intentional (homicidal or suicidal) or unintentional (accidental) resulting from sudden exposure to thermal energy generated by agent host interaction. Criteria of selection of cases:-

1. All cases of burn injuries that have a definite history of flame burns were taken for the study.

2. The cases with different duration and survival times were studied.

3. Burn injuries due to electrocution, chemical and corrosives were not included.

4. Decomposed bodies and bodies with no specific history were not included.

Skin tissue was taken from the burnt and junctional area of the burnt and unburnt region and preserved in $10 \%$ formalin for fixation. The fixed tissues were processed, stained with routine $\mathrm{H} \& \mathrm{E}$ staining and subjected to histopathological examination.

The data was collected and compiled in an excel sheet and analyzed using SPSS (Software Package for Social Studies) version 20, and chi-square test and percentages were applied to find out any significant statistical difference between different groups, and if required, a logistic regression test was applied.

\section{Results}

Histopathological examination of normal human skin revealed that it has two layers-outer epidermis and the inner dermis. The epidermis consists of five layers and is separated from the dermis by a basement membrane. The dermis forms the bulk of skin and consists of an upper papillary layer and the lower reticular layer. It is composed of mature, fibrous connective tissue that contains capillaries, sweat glands, sebaceous glands, hair follicles, and nerve endings. The dermis is attached to underlying loose connective tissue, which consists primarily of adipose tissue (Figure 1).

As shown in Table 1, redline of demarcation was present in $39 \%$ of cases and absent in $61 \%$ of cases (Figure 2). Redness was present in $40 \%$ of cases and absent in $60 \%$ of cases. Blisters were present in $30 \%$ of cases and absent in $70 \%$ of cases. Pus was present in $61 \%$ of cases and absent in $39 \%$ of cases. Granulation Tissue was present in $51 \%$ of cases.

As shown in Table 2, Separation of epithelium and breaking of epithelium were present in $99 \%$ of cases, respectively. Vacuolization was present in $71 \%$ of cases. Petechial hemorrhages was present in $33 \%$ of cases. Epithelial cells were elongated and flattened in $72 \%$ of cases, respectively.

As shown in Table 3, Capillary dilatation was present in $59 \%$ of cases. Edema and congestion were present in 57 and $45 \%$ of cases, respectively. Margination of leucocytes was present in $67 \%$ of cases. Infiltration of leucocytes was present in $95 \%$ of cases.

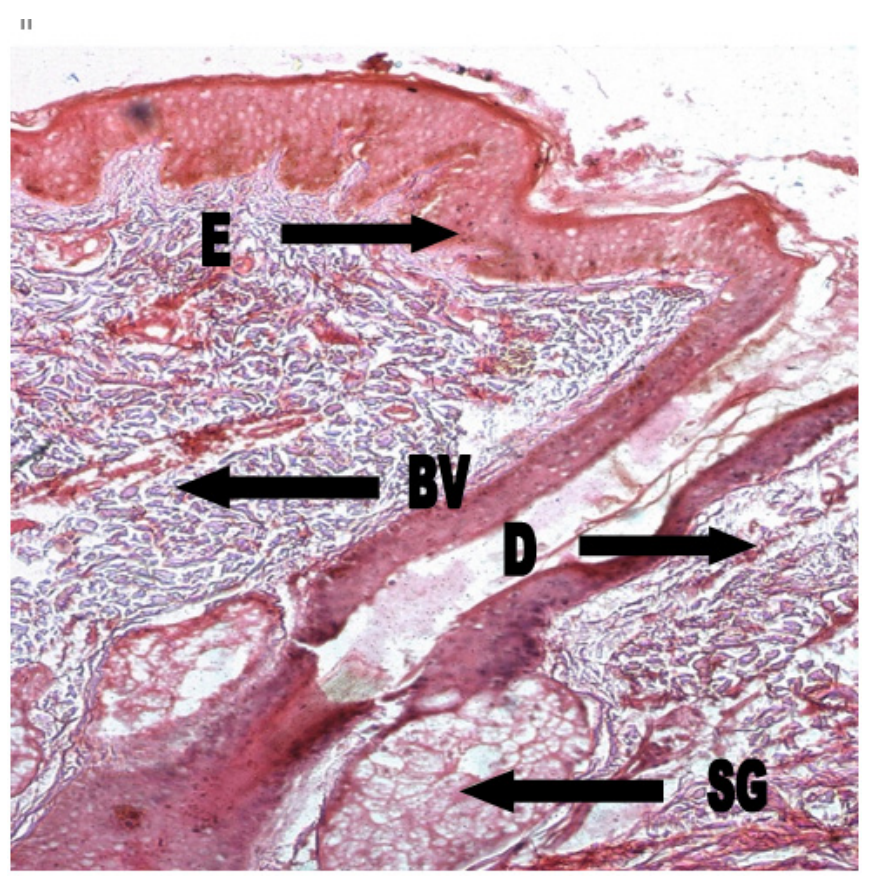

Figure 1: Photomicrograph of histology of normal unburnt skin showing intact epidermis $[E]$, and dermis[D]showing redline of demarcation ( $\mathrm{H} \& \mathrm{E} ; 20 \mathrm{x})$

Table 1: Incidence and distribution of gross features of burnt skin

\begin{tabular}{lll}
\hline & Present & Absent \\
\cline { 2 - 3 } Gross features of burnt skin & No. (\%) & No. (\%) \\
\hline Red line of demarcation & $39(39)$ & $61(61)$ \\
Redness & $40(40)$ & $60(60)$ \\
Blisters & $30(30)$ & $70(70)$ \\
Pus & $61(61)$ & $39(39)$ \\
Granulation Tissue & $51(51)$ & $49(49)$ \\
\hline
\end{tabular}

Chi-square $=23.3 ; p$-value $=.000$ 
On the $3^{\text {rd }}$ day post-burn, the burn wound revealed separation of the epidermis from dermis and breaking of epithelium, vacuolization of epidermal and dermal cells, petechial hemorrhages, congested and dilated capillaries with areas of necrosis, and formation of immature granulation tissue. The inflammatory infiltrate consisted mainly of polymorphonuclear leucocytes [Figure $3(\mathrm{a}, \mathrm{b}, \mathrm{c})]$. On the $3^{\text {rd }}$ to $7^{\text {th }}$ day postburn, the burn wound showed the presence of elongated and flattened epithelial cells. The inflammatory infiltrate consisted of lymphocytes and macrophages in the burn wound (Figure 4). On the $7^{\text {th }}$ day post-burn, the burn wound revealed epidermal regeneration, neo-proliferation of small-sized blood vessels, inflammatory cells infiltration consisting primarily

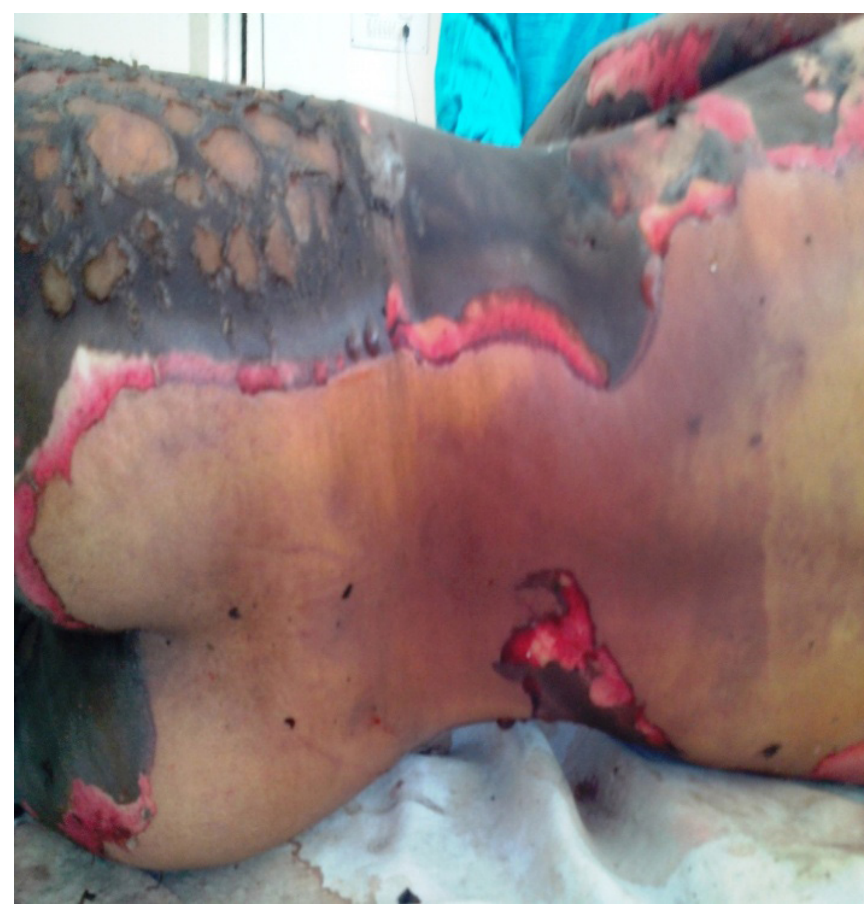

Figure 2: Photograph of burnt skin containing blood vessel [BV] \& sebaceous gland [SG]

Table 2: Incidence of Histopathological findings of Burnt skin

\begin{tabular}{lll}
\hline Burnt Skin & Total number of cases & Percentage (\%) \\
\hline Separation of epithelium & 99 & $99 \%$ \\
Breaking of epithelium & 99 & $99 \%$ \\
Vacuolization & 71 & $71 \%$ \\
Petechial hemorrhages & 33 & $33 \%$ \\
Epithelial cells elongation & 72 & $72 \%$ \\
Epithelial cells Flattening & 72 & $72 \%$ \\
\hline Table 3: Incidence of Histopathological findings of Junctional skin \\
\hline Junctional Skin & Total number of cases & Percentage (\%) \\
\hline Capillary dilatation & 59 & $59 \%$ \\
Oedema & 57 & $57 \%$ \\
Congestion & 45 & $45 \%$ \\
Margination of Leucocytes & 67 & $67 \%$ \\
Infiltration of Leucocytes & 95 & $95 \%$ \\
\hline
\end{tabular}

of macrophages, lymphocytes, fibroblasts, and the presence of immature granulation tissue(Figure 5).On the $14^{\text {th }}$ day post-burn, the burn wound revealed repair by regeneration, increased collagen deposition, fibrosis, and granulation tissue formation. In addition, it was infiltrated with fibroblasts, macrophages, and lymphocytes (Figure 6).

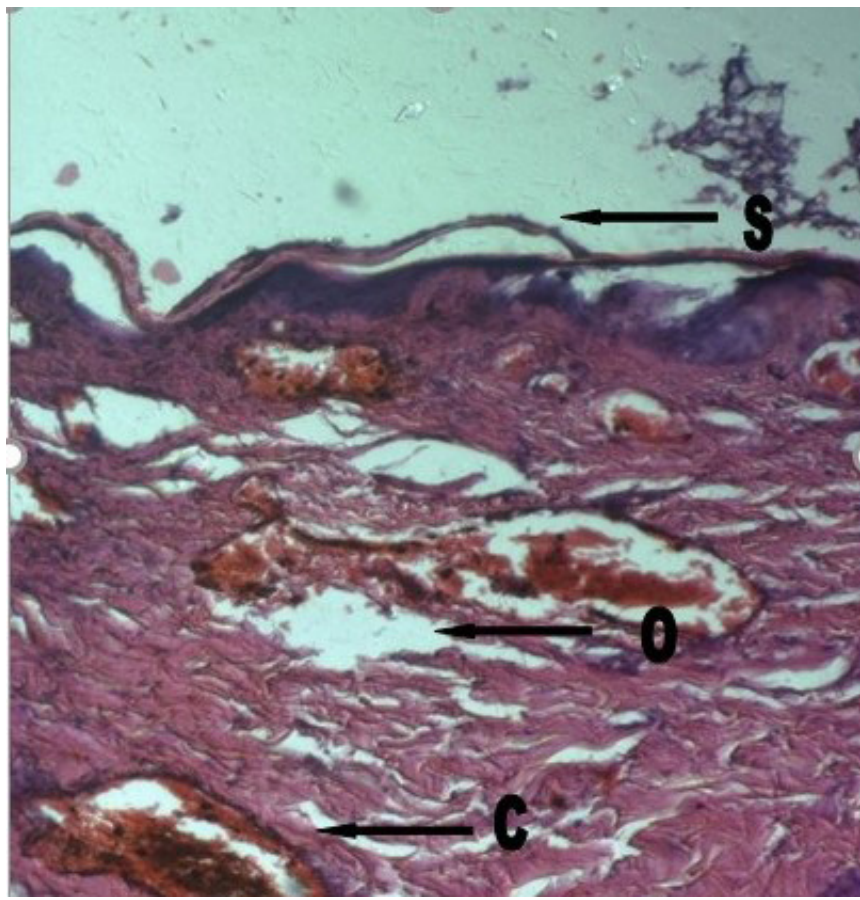

Figure 3a: Photomicrograph of skin, 3 days post-burn showing congestion $[\mathrm{C}]$, edema $[\mathrm{O}]$ and separation of epidermis from dermis [S] (H\&E; 10X)

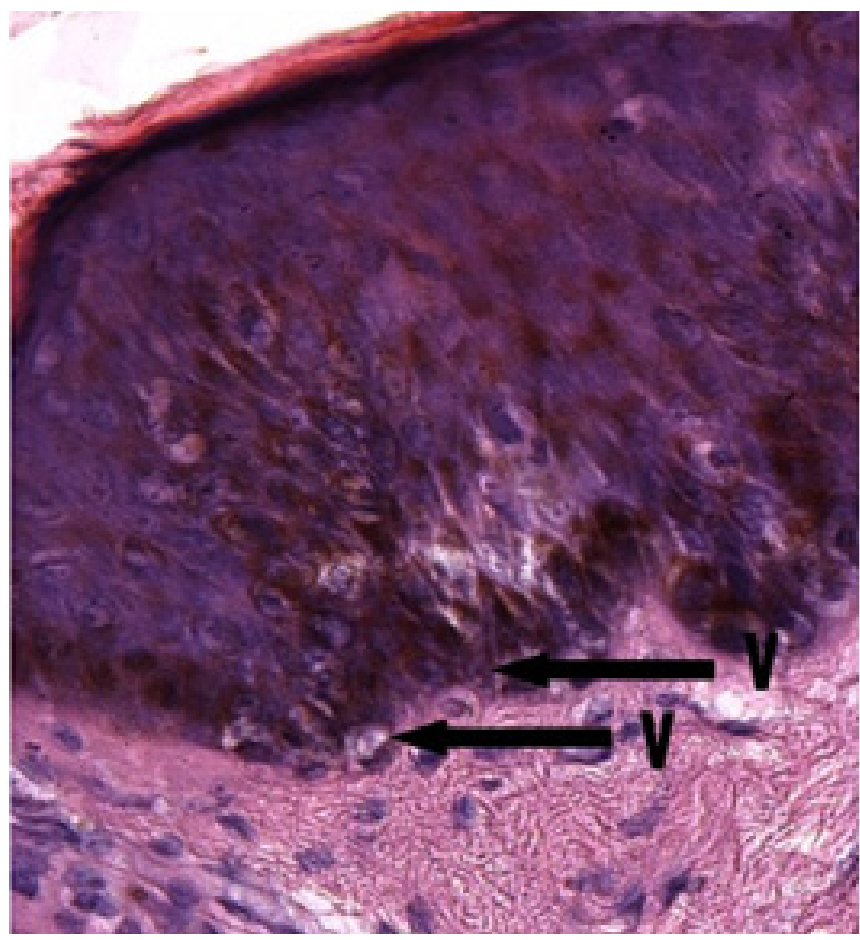

Figure $3 \mathrm{~b}$ : Photomicrograph of skin, 3 days post-burn showing vacuolization $[\mathrm{V}]$ of basal cell layers $(\mathrm{H} \& \mathrm{E} ; 40 \mathrm{x})$ 


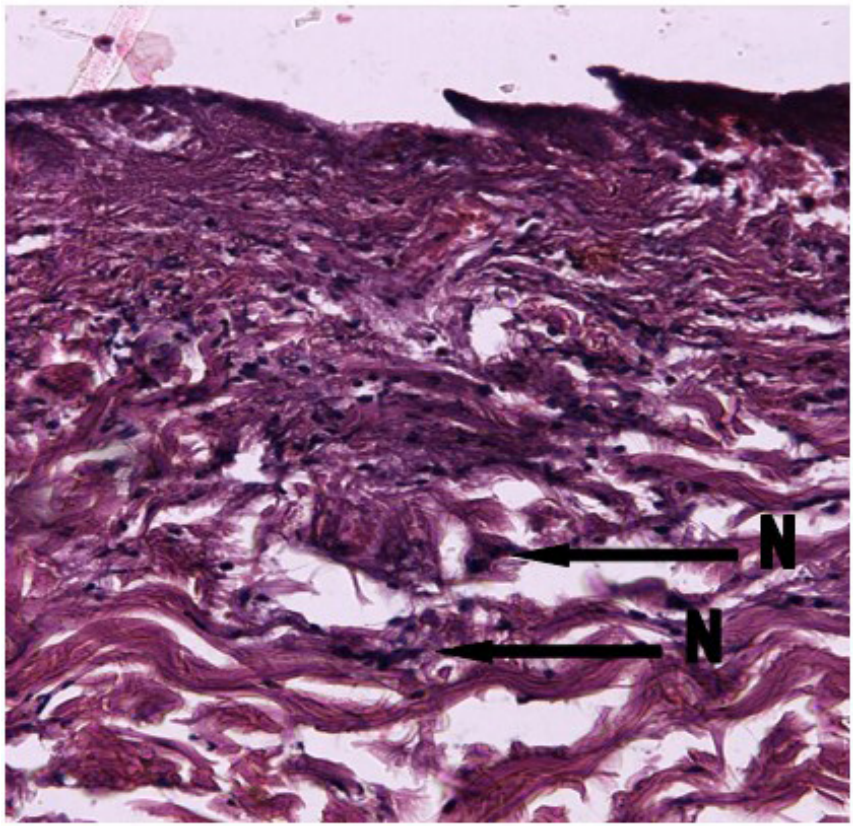

Figure 3c: Photomicrograph of skin, 3 days post-burn showing dermal infiltration by neutrophils [N] (H\&E; 20x)

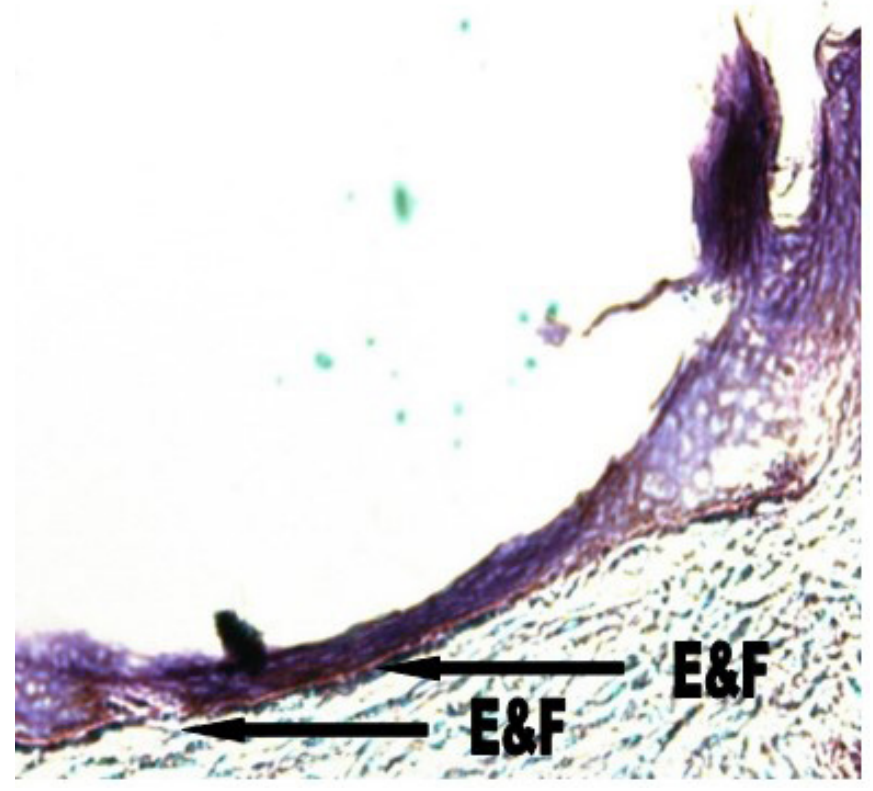

Figure 4: Photomicrograph of skin, 3 to 7 days post-burn showing elongation \& flattening [E\&F] of basal epithelial cells (H\&E; 20x)

\section{Discussion}

The histopathological findings of burnt skin are initially due to direct effects of thermal injury and subsequently due to inflammatory healing response. ${ }^{5}$ Therefore, it could be possible to estimate the vitality and age of burns by examining the order and time at which various cellular components of the healing process are present in burn wounds.

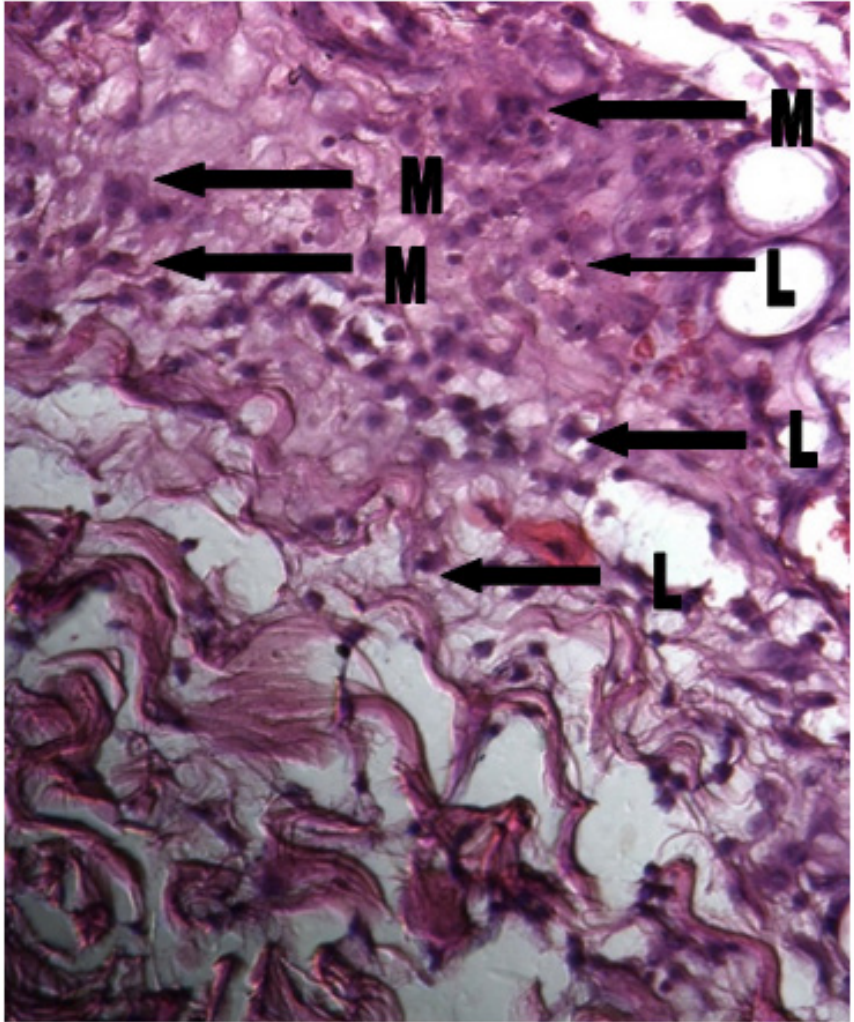

Figure 5: Photomicrograph of skin, 7 days post-burn showing dermal infiltration by lymphocytes [L] \& macrophages [M] (H\&E; 20x)

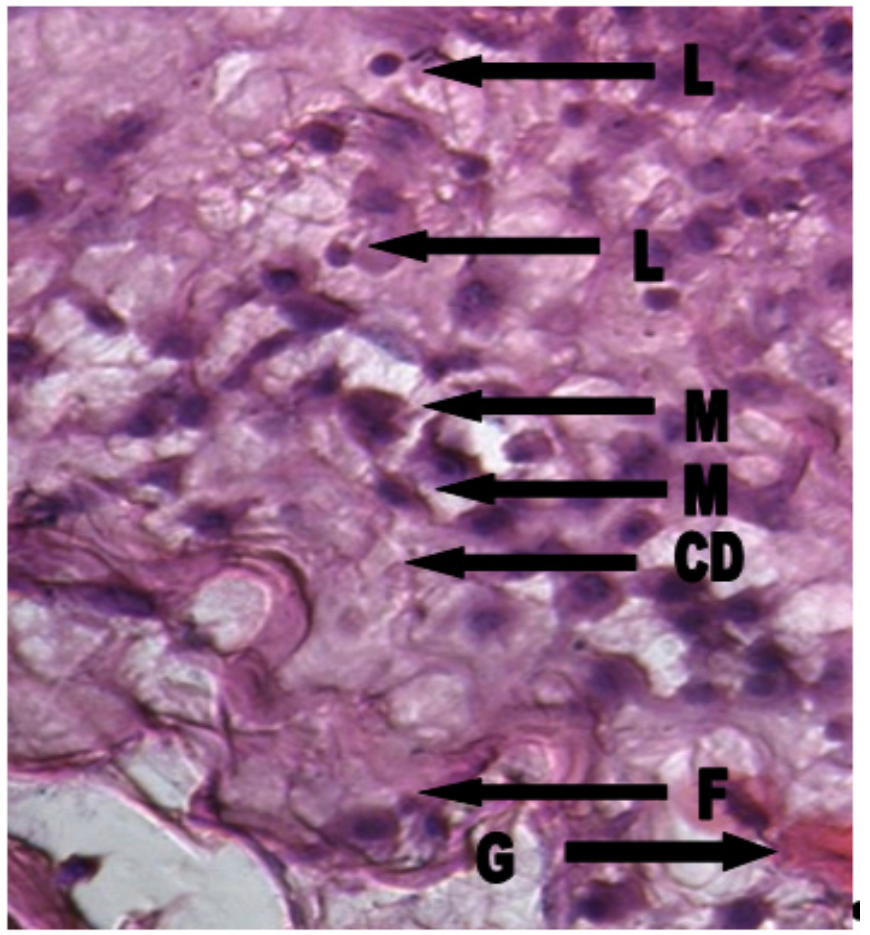

Figure 6: Photomicrograph of skin,14days post-burn showing Collagen deposition [CD], fibrosis [F], granulation tissue [G], and dermal infiltration by macrophages\& lymphocytes (H\&E; 20x) 
Histopathological examination of the edge of a burn, including both the burnt area and adjacent grossly unburnt skin, may reveal vital reaction microscopically, consisting of acute inflammation, hemorrhage, edema, necrosis, and vertical streaming epidermal nuclei and homogenization of the dermal collagen. Skin shows petechial hemorrhages in deeper layers, epithelial cells are elongated, flattened and stained deeply with hematoxylin and eosin and vacuolization of epidermal and dermal layers is prominently seen. These findings help in differentiating antemortem burn from post-mortem burn. ${ }^{6-8}$

In the present study, histopathological examination of burnt and junctional skin, three days post-burn, revealed separation of the epidermis from dermis and breaking of epithelium, vacuolization of epidermal and dermal cells, petechial hemorrhages, congested and dilated capillaries with areas of necrosis, and formation of immature granulation tissue. The inflammatory infiltrate consisted mainly of polymorphonuclear leucocytes in initial stages with gradual involvement of lymphocytes and macrophages.

Haggag $\mathrm{OG}$ et al. in their study observed that on the 3rd-day post-burn, upper layers of dermis showed ulceration, and deeper layers of dermis showed the formation of granulation tissue, diffuse congested capillaries, tissue edema with areas of necrosis. Few tiny perivascular hemorrhages were present in the deep dermis and collagen was destructed. Infiltration of neutrophils was present in burn wounds of moderately-burned patients, but a few neutrophils were present in severely burned patients. ${ }^{9}$

Tarran et al. in their study concluded that the neutrophils were the first inflammatory cells to infiltrate the wound. ${ }^{10}$ Peng et al. observed that infiltrative reaction of leucocytes started at 3rd-day post-burn in victims who sustained moderate burns, but in severe burns, there was no infiltration until 1-week afterburn. The infiltration of neutrophils is due to a local increase in a neutrophil chemo-attractant. The delayed neutrophil infiltration in more severe burn wounds was related to the impaired production of local chemokines. ${ }^{11}$

RJ Brennen, in his study, observed the presence of gross edema, separation of collagen fibers and separation of epidermis almost entirely from the underlying dermis. The capillaries of the dermis were dilated, and congestion was present. In addition, he observed increased numbers of round cells and polymorphonuclear leucocytes in the perivascular tissue. The deeper layers of the dermis showed granulation tissue containing numerous thrombosed capillaries surrounded by areas of microscopic debridement and loss of structure. ${ }^{12}$

$\mathrm{Xu}$ et al., on day three post-burn, observed vacuolization of epidermal cells, hyaline degeneration in collagen dermis, and infiltration of the dermis by inflammatory cells consisting mainly of neutrophils. ${ }^{13}$

In the present study, 3 to 7 days' post-burn biopsies showed elongated and flattened epithelial cells. The inflammatory infiltrate consisted of lymphocytes and macrophages in the burn wound. RJ Brennen, in his study, observed fragmentation of the thermally coagulated tissues, microscopic evidence of granulation, and infiltration of the burn wound with lymphocytes and macrophages. Xu et al. on day 5 post-burn, observed superficial tissues in the dermis were liquefactive necrotized, and exfoliated. The dermis was infiltrated with inflammatory cells consisting mainly of neutrophils and occasional macrophages. A similar result was observed by Haggag $\mathrm{OG}$ et al in their study.

In the present study, 7 days' post-burn biopsies showed epidermal regeneration, congested blood vessels, inflammatory cells infiltration consisting primarily of macrophages, lymphocytes and fibroblasts, and the presence of immature granulation tissue. Haggag OG et al. in their study observed that on $7^{\text {th }}$ day post-burn, the epidermis showed regeneration from the basal layer. Congested blood vessels, collagen deposition and edema, were detected in the dermis with the appearance of fibroblasts in clusters. In addition, the presence of neutrophils, lymphocytes, plasma cells, and a few mononuclear cells was noticed in the burn wound. Peng et al found a large number of leucocytes in burn wounds on the 7th-day post-burn. The cellular components consisted of polymorphonuclear leucocytes in the majority and a few lymphocytes and macrophages. Tarran et al. observed that when macrophages are abundant, the wound is probably a few days to weeks old.

In the present study, 2 weeks' post-burn biopsies revealed repair by regeneration, granulation tissue formation, fibroblasts, macrophages, and lymphocytes in burn wounds. Haggag OG et al., in their study on $14^{\text {th }}$ day post-burn observed the same. They observed that there was epidermal growth, collagen fibers of the dermis were denser than normal, and numerous scattered fibroblasts. Mononuclear cells were the main cellular components in the burn wound. Tarran et al. and Peng et al. also observed the same. They found a formation of frank granulation tissues, neo-proliferation of blood vessels, and predominantly mononuclear cells in the burn wound. RJ Brennen, in his study, observed that between the $12^{\text {th }}$ day to $18^{\text {th }}$ day, the morphological structure of the upper layer of the dermis was entirely lost. Dissection of the collagen fibers and vacuolization were still evident. In some areas, there were still present some nests of white cells. Xu et al., on day 15 postburn, observed that actively proliferated fibroblasts and neoformative capillaries were visible in the dermis, accompanied by the infiltration of lymphocytes.

\section{Conclusion}

The present study concluded that its histopathological evaluation can fairly estimate the burn wound vitality and age. Such estimation is of paramount importance, particularly in criminal cases, when the victim is killed by some other means. Later, the body is burnt to conceal the crime and make it appear like death from burning.

\section{References}

1. Sawhney CP, Ahuja RB, Goel A. Burns in India: Epidemiology and Problems in Management. Indian Journal of Burns 1993; 1(1): 1 . 
2. Ceechi R. Estimating Wound Age: Looking into the future. Int. J Legal Med 2010; 124(6):523-526

3. Rackallio J. Enzyme Histochemistry of Vital and Postmortem Skin Wounds. Journal of Forensic Medicine 1966; 13(2): 85.

4. Vij K. Thermal Deaths. In: Textbook of Forensic Medicine and Toxicology. 2nd ed. New Delhi. B I Churchill Livingstone. 2002.p. 319-328.

5. Sevitt S. Histopathological changes in burned skin. Burns. Pathology and Therapeutic Applications. Butterworth and Co. Ltd. 1957.p.18-27.

6. Reddy KSN, Murty OP. Thermal Deaths. The Essentials of Forensic Medicine and Toxicology. 34 ${ }^{\text {th }}$ ed. New Delhi. 2017. p. 305.

7. Rao D. Thermal Injuries. http://www.forensicpathologyonline. com/

8. El-Sayed YS. Time Course of Histomorphologic Features during Chronic Burn Wound Healing. Forensic Medicine and Anatomy Research. 2016;4:1-6

9. Haggag OG, Fouda AA, Eldin AAIS, Al-Aziz TAA, Mahmoud
AA. Biochemical, Histopathological and Immunohistochemical Study of Burn Lesions in Patients Admitted to Benha Educational Hospital: A Prospective Study. Egyptian J. Forensic Sci. Appli. Toxicol. 2013;13(2):83-106

10. Tarran S,Langlois NE, Dziewulski P, Sztynda T.Using the inflammatory cell infiltrate to estimate the ageof human burn wounds: A review and immune-histochemical study.Med Sci Law. 2006;46(2):115-126.

11. Peng D, Huang W, Shenhai A, Wang S. Clinical significance of leukocyte infiltrative response in deep wound of patients with major burns. Burns. 2006; 32(8): 946-950.

12. Brennan RJ, Rovatti B. Experimental Thermal Burns- A study of the immediate and delayed histopathological changes of the skin. www.aloe.com/pdfiles/experimental thermal burns. pdf.

13. Xu RX, XiaS,Bradford SW. Physiological Healing Procedure and Histological Observation on Deep Second-Degree Burns Treated with BRT with MEBT/MEBO. Burns Regenerative Medicine and Therapy.2004. p.106-111. 